\title{
Growth and decomposition of aligned and ordered PdO nanoparticles
}

\author{
Simon Penner a , Di Wang ${ }^{\text {b }}$, Bernd Jenewein ${ }^{\text {a }}$, Harald Gabasch ${ }^{\text {a, b }}$, Bernhard Klötzer ${ }^{\text {a }}$, \\ Axel Knop-Gericke ${ }^{\text {b }}$, Robert Schlögl ${ }^{\text {b }}$, Konrad Hayek ${ }^{\text {a }}$ \\ Institute of Physical Chemistry, University of Innsbruck, Innrain 52a, A-6020 Innsbruck, Austria \\ Department of Inorganic Chemistry, Fritz-Haber-Institut of the Max-Planck Society, \\ Faradayweg 4-6, D-14195 Berlin, Germany \\ *Fax: 0043512507 2925. Email: simon.penner@uibk.ac.at
}

The formation, thermal decomposition, and reduction of small PdO particles were studied by high-resolution transmission electron microscopy and selected area electron diffraction. Welldefined Pd particles (mean size of 5-7 nm) were grown epitaxially on $\mathrm{NaCl}(001)$ surfaces and subsequently covered by a layer of amorphous $\mathrm{SiO}_{2}(25 \mathrm{~nm})$, prepared by reactive deposition of $\mathrm{SiO}$ in $10^{-2} \mathrm{~Pa} \mathrm{O}_{2}$. The resulting films were exposed to molecular $\mathrm{O}_{2}$ in the temperature range of $373-673 \mathrm{~K}$, and the growth of PdO was studied. The formation of a PdO phase starts at $623 \mathrm{~K}$ and is almost completed at $673 \mathrm{~K}$. The high-resolution experiments suggest a topotactic growth of PdO crystallites on top of the original Pd particles. Subsequent reaction of the PdO in $10 \mathrm{mbar}$ $\mathrm{CO}$ for $15 \mathrm{~min}$ and thermal decomposition in $1 \mathrm{bar} \mathrm{He}$ for $1 \mathrm{~h}$ were also investigated in the temperature range from 373 to $573 \mathrm{~K}$. Reductive treatments in $\mathrm{CO}$ up to $493 \mathrm{~K}$ do not cause a significant change in the $\mathrm{PdO}$ structure. The reduction of $\mathrm{PdO}$ starts at $503 \mathrm{~K}$ and is completed at $523 \mathrm{~K}$. In contrast, $\mathrm{PdO}$ decomposes in 1 bar $\mathrm{He}$ at around $573 \mathrm{~K}$. The mechanism of $\mathrm{PdO}$ growth and decay is discussed and compared to results of previous studies on other metals, e.g., on rhodium.

\section{INTRODUCTION}

Palladium is one of the most active catalysts for total oxidation of hydrocarbons, e.g., of methane combustion, and also for partial oxidation, e.g., of ethene to acetic acid.[1,2,3,4,5,6,7,8] Hence, there is a growing need to understand the key parameters determining the reaction mechanisms. One of the most important parameters crucially influencing the catalytic activity of Pd-based catalysts is their chemical state under reaction conditions which is known to switch between metallic and oxidic under typical reaction conditions,[6,9,10,11] depending on $\mathrm{O}_{2}$ pressure and temperature. Numerous studies on the interaction of $\mathrm{Pd}$ single crystal surfaces[12,13,14,15,16,17,18,19] and of supported Pd catalysts [20,21,22,23] with oxygen have been performed, but the influence of oxide formation on the catalytic activity still remains a matter of discussion. It was reported that at low reaction temperature, $\mathrm{PdO}$ is the active phase in methane combustion and that the catalytic activity decreases upon conversion of $\mathrm{PdO}$ to $\mathrm{Pd}$ with increasing temperature, [10] but it was also observed by other authors that metallic Pd is a highly active phase in methane combustion.[7] Comparatively little studies on the interaction of Pd with oxygen have been conducted by electron microscopy techniques. Lyubovsky et al.[24] and Datye et al.[11] reported on microstructural modifications of impregnated $\mathrm{Pd}-\mathrm{Al}_{2} \mathrm{O}_{3}$ catalysts during the transformation from $\mathrm{Pd}$ to $\mathrm{PdO}$ and established a correlation to the reactivity in methane oxidation. Electron microscopy was also used to characterize the state of $\mathrm{Pd}$ during other hydrocarbon oxidation reactions.[3,25,26] Detailed high-resolution transmission electron microscopy (HRTEM) studies after annealing small $\mathrm{Pd}$ particles grown epitaxially on $\mathrm{MgO}$ single crystals and microcubes in oxygen atmosphere were provided by Henry and co- 
workers.[27,28,29] $\mathrm{PdO}$ formation on small $\mathrm{Pd}$ particles supported by $\gamma-\mathrm{Al}_{2} \mathrm{O}_{3}$ upon heating in 1 bar oxygen in the temperature range of 623-1193 $\mathrm{K}$ has also been studied by Chen and Ruckenstein.[30] They observed the formation of pits and cavities on the crystallites along with a spreading and a subsequent rupture and fragmentation at $773 \mathrm{~K}$. Similar effects have been reported by Chen and Schmidt[31] after heating Pd-Pt alloy particles in air at elevated temperature.

The aim of the present contribution is twofold: First, we present a detailed study of the oxidation of small Pd particles, starting from epitaxially grown nanocrystals embedded in a thin amorphous $\mathrm{SiO}_{2}$ film. We take advantage of the unique properties of our previously described thin film model catalysts,[32] i.e., well-defined particle shapes, improved plan-view, imaging by HRTEM, a large contact area between metal and support, and better opportunities for selected area electron diffraction (SAED) due to large numbers of particles contributing to the diffracted beam. We are attempting to exploit these properties to prepare well-defined PdO nanoparticles. On the other hand, we shall focus on the differences in reduction by $\mathrm{CO}$ and decomposition in $\mathrm{He}$ atmosphere, respectively, in close correlation to previous experiments on ethane oxidation.[33]

\section{EXPERIMENT}

A high-vacuum chamber (base pressure of $10^{-4} \mathrm{~Pa}$ ) was used to prepare the $\mathrm{SiO}_{2}$-supported $\mathrm{Pd}$ catalysts. Pd particles (nominal thickness of $0.6 \mathrm{~nm}$ ) were grown by electron-beam deposition at $623 \mathrm{~K}$ on vacuum-cleaved $\mathrm{NaCl}(001)$ single crystal surfaces. The film thickness was monitored by a quartz crystal microbalance. The samples were allowed to cool to room temperature and subsequently covered by a layer of amorphous silica (nominal thickness of $25 \mathrm{~nm}$ ), prepared by reactive deposition of $\mathrm{SiO}$ in $10^{-2} \mathrm{~Pa} \mathrm{O}_{2}$. The resulting films were floated and rinsed with distilled water, dried, and finally mounted on gold grids for electron microscopy. Oxidative (1 bar $\mathrm{O}_{2}$ for $1 \mathrm{~h}, 373-673 \mathrm{~K}$ ) and reductive (10 mbar $\mathrm{CO}, 990 \mathrm{mbar} \mathrm{He}$ for $15 \mathrm{~min}, 323-523 \mathrm{~K}$ ) treatments and thermal annealing ( 1 bar He for $1 \mathrm{~h}, 473-573 \mathrm{~K}$ ) were performed in a circulating batch reactor. The structure and morphology of the thin films in the as-grown state and upon oxidative and reductive treatments were monitored by HRTEM and SAED with a Zeiss EM 10C microscope and a Philips CM200 field emission gun (FEG) microscope, equipped with a Gatan imaging filter.

\section{RESULTS AND DISCUSSION}

\section{A.Formation of the PdO phase}

Figure 1(a) shows the as-grown state of the $\mathrm{Pd} / \mathrm{SiO}_{2}$ catalyst to which all the resulting structural and morphological changes will be referenced. The Pd particles appear as gray and black dots while the $\mathrm{SiO}_{2}$ support is amorphous in the as-grown state and does not contribute a considerable contrast. The black particles appear in perfect Bragg orientation and the gray ones are slightly tilted out of Bragg position. Most particles exhibit rounded outlines indicating the presence of higher-indexed facets,[32] while some others exhibit randomly arranged facets and only few show square or rectangular outlines. The cuboctahedral habit of the particles was extracted from previous weak-beam dark field and HRTEM images of analog $\mathrm{Al}_{2} \mathrm{O}_{3}$-based $\mathrm{Pd}$ catalysts.[32] [The SAED patterns [Fig. 1(b)] show mainly reflections of fcc Pd, the most intense ones measured at $\sim 2.26, \sim 1.94$, and $\sim 1.36 \AA$, corresponding to $\operatorname{Pd}(111), \operatorname{Pd}(220)$, and $\operatorname{Pd}(220)$ lattice distances $\left[d_{111}(\right.$ theor $)=2.245 \AA, d_{200}($ theor $)=1.945 \AA$, and $d_{220}$ (theor) $\left.=1.375 \AA\right]$. Hence, most particles are oriented either along a [100] or a [110] zone axis. HRTEM images[32] (not shown here) exhibit Pd fcc (200) lattice fringes including an angle of $45^{\circ}$ with the cuboctaeder edges. 

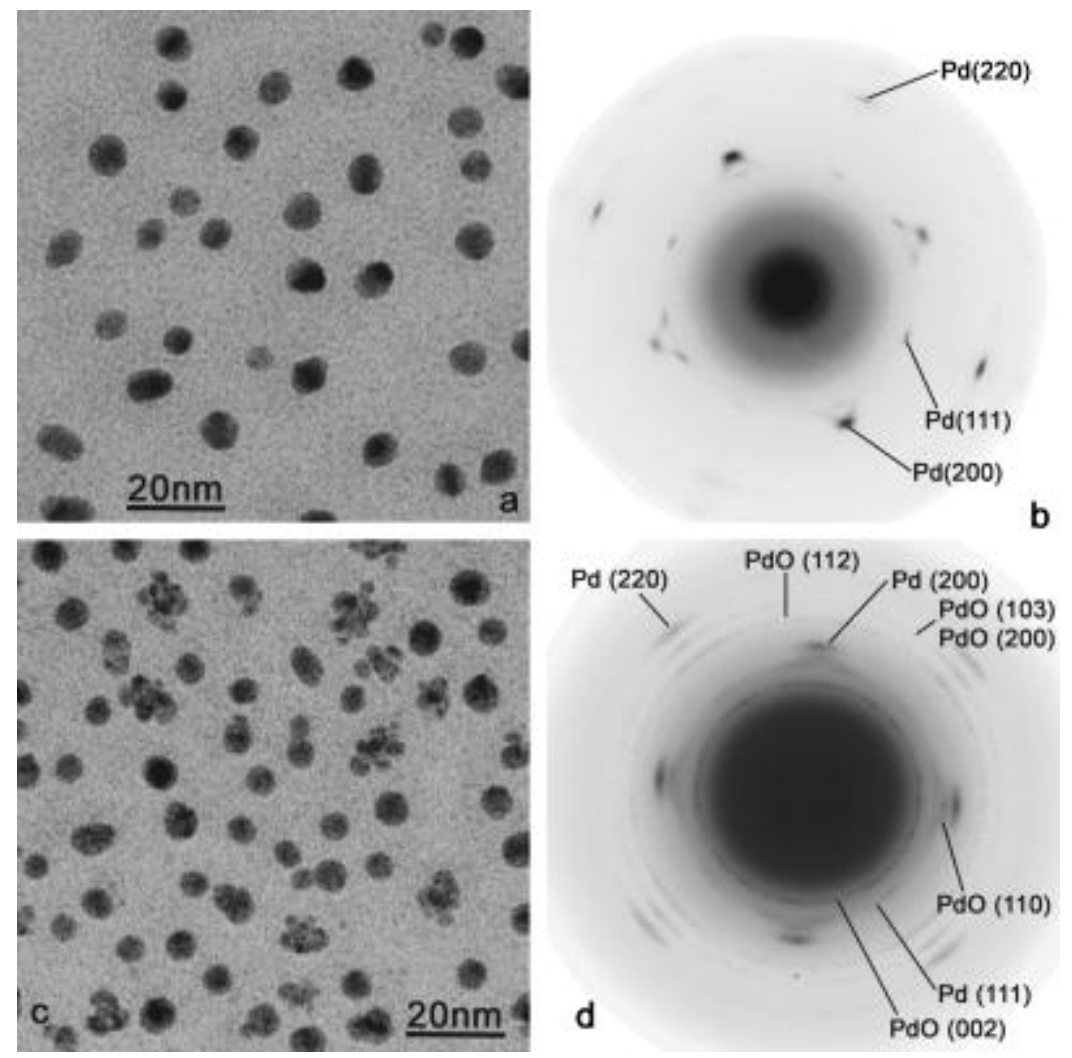

Fig. 1. The $\mathrm{Pd} / \mathrm{SiO}_{2}$ catalyst as deposited (a), with the corresponding SAED pattern (b), and after oxidation at $623 \mathrm{~K}$ in 1 bar $\mathrm{O}_{2}$ for $1 \mathrm{~h}(\mathrm{c})$, corresponding SAED pattern $(\mathrm{d})$.

To study the growth of the PdO phase, we subjected the films to oxidative treatments between room temperature and $673 \mathrm{~K}$. Up to $573 \mathrm{~K}$, no significant changes in particle structure or morphology could be noticed. The particles retain their rounded outlines and the SAED patterns show only broadened Pd reflections indicating a slight increase of orientational disorder. However, first changes of the particle structure are seen after oxidation at $623 \mathrm{~K}\left(1 \mathrm{bar} \mathrm{O}_{2}\right.$ for 1 h) [Fig. 1(c)]. Although a large particle fraction still keeps the rounded outlines typical for the asdeposited state, a considerable number of particles have started to disintegrate. This beginning transformation does also affect the SAED patterns [Fig. 1(d)]. Although the broadened Pd reflections are still present, the diffraction pattern shows a number of new reflections corresponding to lattice distances of $\sim 3.04, \sim 2.65, \sim 216, \sim 170$, and $\sim 1.53 \AA$, which can be attributed to tetragonal $\mathrm{PdO}$ (space group: $\mathrm{P} 42 / \mathrm{mmc}$, lattice constants $a=3.043 \AA$ and $c=5.337$ $\AA)\left[d_{100}(\right.$ theor $)=3.046 \AA, d_{002}($ theor $)=2.66 \AA, d_{101}($ theor $)=2.644 \AA, d_{110}$ (theor) $=2.153 \AA$, $d_{112}($ theor $)=1.674 \AA, d_{103}$ (theor) $=1.535 \AA$, and $d_{200}$ (theor) $=1.522 \AA$ ].[34] A complete listing of the reflections and their assignment to tetragonal PdO and fcc Pd is given in Table I. We note that the Pd particles and the tetragonal PdO phase formed during oxidation remain at least partially ordered and are epitaxially aligned to each other. The $\operatorname{PdO}(110)$ and the $\operatorname{PdO}(200)$ reflections in Fig. 1(d) appear at the same azimuth as the $\operatorname{Pd}(200)$ and the $\operatorname{Pd}(220)$ spots, respectively. This implies oriented (topotactic) growth of the $\mathrm{PdO}$ phase with respect to the $\mathrm{Pd}$ particles in the crystallographic relation $\mathrm{PdO}[100] \| \mathrm{Pd}[100]$. Representative HRTEM images of either species detected at this stage of oxidation are shown in Figs. 2(a)2(b). A single Pd particle on its [100] zone axis is shown in Fig. 2(a), with two sets of perpendicular (200) lattice fringes at an angle of $45^{\circ}$ with respect to the (111) particle side faces. In contrast, Fig. 2(b) shows a highresolution image of a small $\mathrm{PdO}$ particle exhibiting (002) lattice fringes $(d \sim 2.64 \AA$ ), surrounded by a disordered phase. Keeping in mind the plan view imaging, we may assume that $\mathrm{PdO}$ is located on top, and not in the core, of the former Pd particle, since a growth mechanism creating a PdO core surrounded by a shell of metallic Pd appears highly improbable. 
TABLE 1. Interplanar distances $d(h k l)(\AA)$ measured on the $\mathrm{Pd} / \mathrm{SiO}_{2}$ catalyst after different oxidative treatments and possible correlation to fcc $\mathrm{Pd}$ and tetragonal $\mathrm{PdO}$

\begin{tabular}{|c|c|c|c|c|c|c|c|c|}
\hline \multirow[b]{3}{*}{$d(h k l)$} & \multicolumn{2}{|c|}{ As deposited } & \multicolumn{3}{|c|}{$\mathrm{O}_{2} 623 \mathrm{~K}$} & \multicolumn{3}{|c|}{$\mathrm{O}_{2} 673 \mathrm{~K}$} \\
\hline & \multicolumn{2}{|c|}{ Assignment } & \multirow{3}{*}{$\begin{array}{l}d(h k l) \\
\text { Expt. }\end{array}$} & \multicolumn{2}{|c|}{ Assignment } & \multirow{3}{*}{$\begin{array}{l}d(h k l) \\
\text { Expt. }\end{array}$} & \multicolumn{2}{|c|}{ Assignment } \\
\hline & Lattice & $d(h k l)$ & & Lattice & $d(h k l)$ & & Lattice & $d(h k l)$ \\
\hline Expt. & plane & Theor. & & plane & Theor. & & plane & Theor. \\
\hline 2.26 & $\overline{P d(111)}$ & 2.245 & 3.04 & $\mathrm{PdO}(100)$ & 3.046 & 3.08 & $\overline{\mathrm{PdO}(100)}$ & $\overline{3.046}$ \\
\hline \multirow[t]{2}{*}{1.94} & $\operatorname{Pd}(200)$ & 1.945 & 2.65 & $\mathrm{PdO}(002)$ & 2.667 & 2.66 & $\mathrm{PdO}(002)$ & 2.667 \\
\hline & & & & $\mathrm{PdO}(101)$ & 2.644 & & $\mathrm{PdO}(101)$ & 2.644 \\
\hline \multirow[t]{9}{*}{1.36} & $\operatorname{Pd}(220)$ & 1.375 & 2.23 & $\operatorname{Pd}(111)$ & 2.245 & 2.17 & $\mathrm{PdO}(110)$ & 2.153 \\
\hline & & & 2.16 & $\mathrm{PdO}(110)$ & 2.153 & 1.69 & $\operatorname{PdO}(112)$ & 1.674 \\
\hline & & & 1.97 & $\operatorname{Pd}(200)$ & 1.945 & 1.55 & $\mathrm{PdO}(103)$ & 1.536 \\
\hline & & & & & & & $\mathrm{PdO}(200)$ & 1.522 \\
\hline & & & 1.70 & $\mathrm{PdO}(112)$ & 1.674 & 1.34 & $\mathrm{PdO}(004)$ & 1.335 \\
\hline & & & & & & & $\mathrm{PdO}(202)$ & 1.332 \\
\hline & & & 1.53 & $\mathrm{PdO}(103)$ & 1.536 & & & \\
\hline & & & & $\mathrm{PdO}(200)$ & 1.522 & & & \\
\hline & & & 1.39 & $\operatorname{Pd}(220)$ & 1.375 & & & \\
\hline
\end{tabular}

A complete listing of the reflections and their assignment to tetragonal $\mathrm{PdO}$ and $\mathrm{fcc} \mathrm{Pd}$ is given in Table 1. We note that the Pd particles and the tetragonal PdO phase formed during oxidation remain at least partially ordered and are epitaxially aligned to each other. The $\operatorname{PdO}(110)$ and the $\operatorname{PdO}(200)$ reflections in Fig. 1(d) appear at the same azimuth as the $\operatorname{Pd}(200)$ and the $\operatorname{Pd}(220)$ spots, respectively. This implies oriented (topotactic) growth of the PdO phase with respect to the $\mathrm{Pd}$ particles in the crystallographic relation $\mathrm{PdO}[100] \| \mathrm{Pd}[100]$. Representative HRTEM images of either species detected at this stage of oxidation are shown in Figs. 2(a)2(b). A single Pd particle on its [100] zone axis is shown in Fig. 2(a), with two sets of perpendicular (200) lattice fringes at an angle of $45^{\circ}$ with respect to the (111) particle side faces. In contrast, Fig. 2(b) shows a high-resolution image of a small PdO particle exhibiting (002) lattice fringes $(d \sim 2.64$ $\AA$ ), surrounded by a disordered phase. Keeping in mind the plan view imaging, we may assume that $\mathrm{PdO}$ is located on top, and not in the core, of the former Pd particle, since a growth mechanism creating a $\mathrm{PdO}$ core surrounded by a shell of metallic Pd appears highly improbable. The PdO phase and the "surrounding" part, possibly a disoriented Pd phase, are separated by a grain boundary. However, it should also be kept in mind that the formed PdO is very sensitive to the electron beam of the microscope and prone to amorphization after a short period of irradiation.

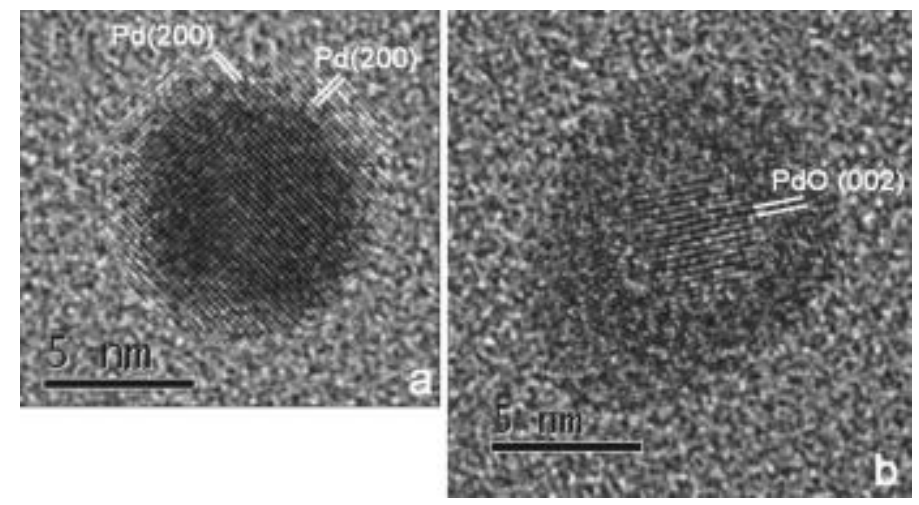

Fig. 2. HRTEM images of the $\mathrm{Pd} / \mathrm{SiO}_{2}$ catalyst after oxidation at $623 \mathrm{~K}$. (a) Single not oxidized Pd particle exhibiting (200) lattice fringes; (b) single PdO grain with (002) lattice fringes. 
Further increasing the oxidation temperature to $673 \mathrm{~K}\left(1\right.$ bar $\mathrm{O}_{2}$ for $\left.1 \mathrm{~h}\right)$ leads to more pronounced disintegration and rupture of the former Pd particles [Fig. 3(a)]. Now almost all particles exhibit the "dispersed" structure, consisting of smaller aggregates, already observed after oxidation at $623 \mathrm{~K}$. These new small particles exhibit a very narrow size distribution and are typically $2-3 \mathrm{~nm}$ in size [see Fig. 3(a) with an inset containing a four-particle line profile].

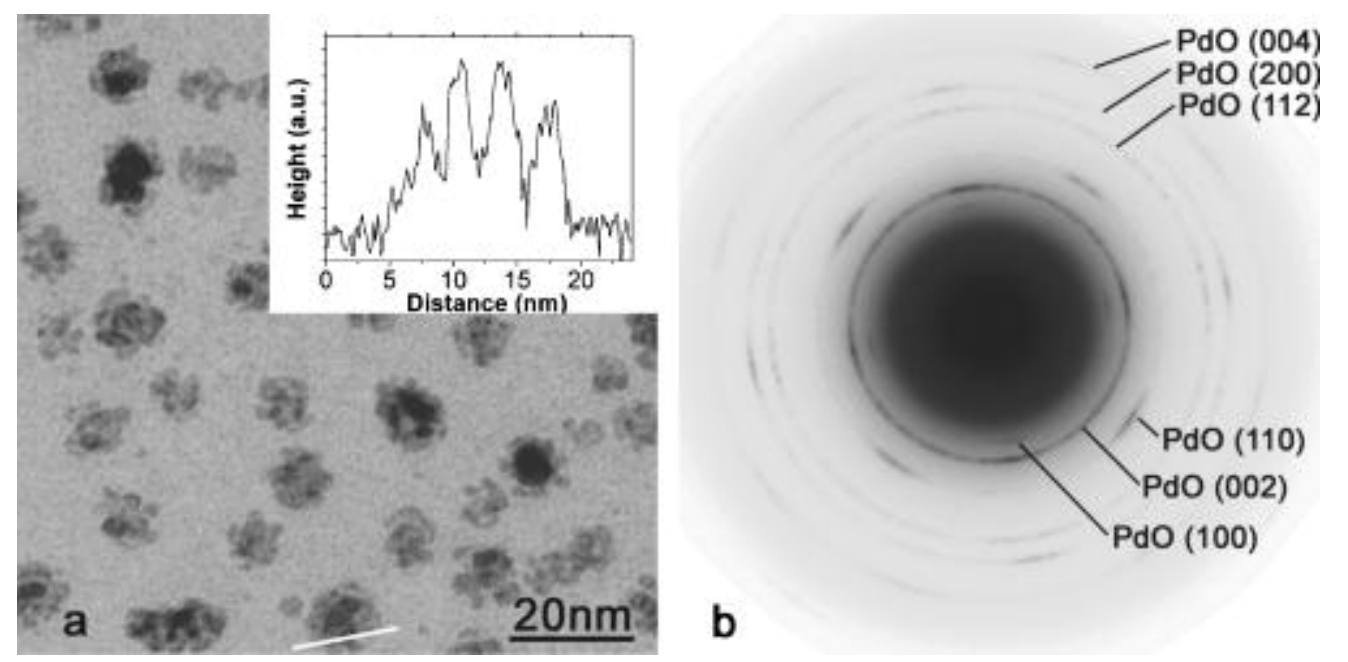

Fig. 3. The $\mathrm{Pd} / \mathrm{SiO}_{2}$ catalyst after an oxidative treatment in 1 bar $\mathrm{O}_{2}$ at $673 \mathrm{~K}$ for $1 \mathrm{~h}$ (a), corresponding SAED pattern (b).

This result is in agreement with studies by Chen and Ruckenstein,[30] who observed a similar structure after oxidation of $\mathrm{Pd}$ particles in 1 bar $\mathrm{O}_{2}$ at $773 \mathrm{~K}$ for $24 \mathrm{~h}$ and tentatively addressed it to a cracking of the crystallites due to stress generated by the more voluminous PdO being formed at some facets of the Pd particles. At this stage the SAED patterns show reflections arising from tetragonal PdO with almost no Pd detectable [Fig. 3(b)]. However, the alignment of $\mathrm{PdO}$ with respect to the former fcc Pd lattice is still pronounced. Broadened diffraction spots, sometimes faint but clearly discriminable, are superposed to the respective PdO ring reflections. This feature is particularly pronounced for $\mathrm{PdO}(100), \operatorname{PdO}(110)$, and $\mathrm{PdO}(200)$. These reflections exhibit a fourfold symmetry: The (100) and (200) spots are aligned in parallel and the (110) spots are rotated by $45^{\circ}$. This result further confirms epitaxial growth in a defined crystallographic relation, as stated above.

HRTEM images of single particles taken after oxidation at $673 \mathrm{~K}$ resemble those taken after oxidation at lower temperatures $(623 \mathrm{~K})$. A three-particle agglomerate is shown in Fig. 4(a), along with a $\mathrm{PdO}$ particle surrounded by crystalline $\mathrm{Pd}$ (upper right corner). Both $\mathrm{PdO}(002)$ lattice fringes and $\operatorname{Pd}(111)$ spacings are easily observable. The particle in the upper right corner is of the type shown in Fig. 2(b). Another PdO grain is seen in Fig. 4(b) (inset), covering most of its Pd precursor. This type of structure is frequently encountered after oxidation at $673 \mathrm{~K}$ and points to a mechanism involving preferential $\mathrm{PdO}$ growth on top of the Pd particles at relatively low temperatures ("incomplete oxidation"), whereas particle edges and metal-support interface are only affected after oxidation at higher temperatures ("complete oxidation"). It is worth to mention that at this oxidation stage, most (former) particles contain either polycrystalline structures in contact with $\mathrm{PdO}$ or, to a lesser extent, small single PdO crystallites seemingly surrounded by disordered structures or by (still crystalline) Pd phase. 


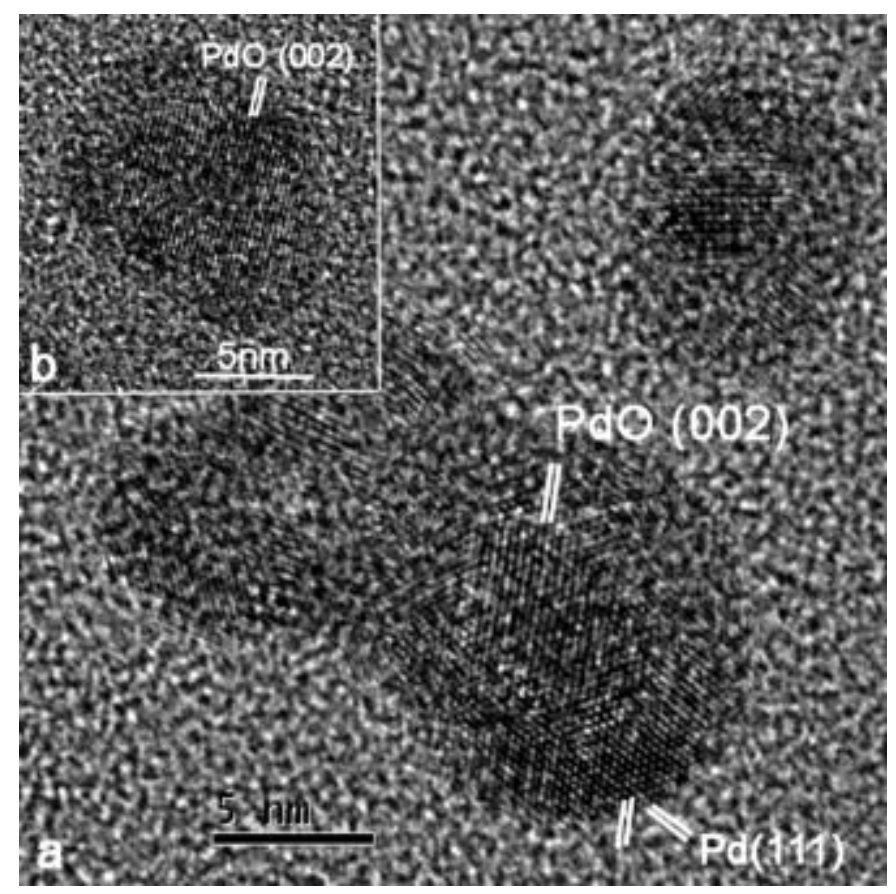

Fig. 4. HRTEM images of the $\mathrm{Pd} / \mathrm{SiO}_{2}$ catalyst after oxidation at $673 \mathrm{~K}$. (a) Three-particle agglomerate consisting of crystalline $\mathrm{Pd}$ and $\mathrm{PdO}$; (b) $\mathrm{PdO}$ particle extending above a former Pd particle.

We compare our observations to recent results on the oxidation of small Pd particles supported by an ordered $\mathrm{Fe}_{3} \mathrm{O}_{4}$ film.[35,36] In this case, the initial formation of interfacial oxides under mild oxidation conditions ( $T=500 \mathrm{~K}$, effective oxygen partial pressure of around $10^{-6} \mathrm{mbar}$ ) and the subsequent spreading of the oxide phase to the $\mathrm{Pd} /$ gas interface were observed. Although the $\mathrm{Pd} / \mathrm{Fe}_{3} \mathrm{O}_{4}$ systems bear some similarities to the thin film system outlined in the present work, the fundamental difference in the growth morphology on the respective supporting oxides $\left(\mathrm{SiO}_{2}\right.$ versus $\mathrm{Fe}_{3} \mathrm{O}_{4}$ ) is most likely due to a more stable $\mathrm{PdO}-\mathrm{Fe}_{3} \mathrm{O}_{4}$ interface compared to $\mathrm{PdO}-\mathrm{SiO}_{2}$. This might in turn favor the preferential oxidation at the $\mathrm{Pd}-\mathrm{Fe}_{3} \mathrm{O}_{4}$ interface.

The growth of $\mathrm{PdO}$ described here is also in contrast with previous studies of the oxidation of other noble metals, e.g., of small Rh particles supported by alumina.[37] In that study it was observed that after oxidation at $575 \mathrm{~K}$, the $\mathrm{Rh}$ metal particle surface was surrounded by a $1 \mathrm{~nm}$ oxidic layer, as evident in high-resolution images, while oxidation at higher temperature $(725 \mathrm{~K})$ resulted in the formation of a shell of hexagonal $\alpha-\mathrm{Rh}_{2} \mathrm{O}_{3}$ epitaxially covering the remaining $\mathrm{Rh}$ metal core, i.e., just the opposite situation as in the case of $\mathrm{PdO} / \mathrm{Pd}$. In analogy, a kinetically stable $\mathrm{O}-\mathrm{Rh}-\mathrm{O}$ trilayer surface oxide was observed during oxidation of a $\mathrm{Rh}(111)$ surface,[38] while three-dimensional $\mathrm{PdO}$ island growth was observed by atomic force microscope (AFM) imaging of $\mathrm{Pd}$ films annealed in $\mathrm{O}_{2}$ at $1173 \mathrm{~K}$.[39] Hence, the growth of $\mathrm{PdO}$ and $\mathrm{Rh}_{2} \mathrm{O}_{3}$ proceeds via different mechanisms and $\mathrm{PdO}$ growth involves the formation of distinct $\mathrm{PdO}$ islands and/or crystallites rather than the formation of a thin adhesive layer.

No changes in either $\mathrm{PdO}$ particle structure or morphology were observed if the oxidation temperature was further raised to $723 \mathrm{~K}$.

\section{B.Stability of PdO under reductive and annealing conditions}

A kinetic study of ethane oxidation on $\mathrm{PdO}$ formed on a polycrystalline $\mathrm{Pd}$ foil performed recently in our group [33] has shown that on stoichiometric PdO, this reaction starts with a partial reduction of the surface towards the metallic state which is responsible for a delayed onset of the reaction. Therefore, we now focused on the behavior of the PdO phase upon a reductive treatment and, in comparison, upon a simple annealing treatment. Instead of hydrogen, $\mathrm{CO}$ was 
chosen as a "mild" reducing agent. The reduction with $\mathrm{CO}$ described in the following was carried out in a mixture of 10 mbar $\mathrm{CO}$, with $\mathrm{He}$ added to 1 bar total pressure for $15 \mathrm{~min}$ at varying temperature. The annealing treatments were conducted in 1 bar pure helium for $1 \mathrm{~h}$.

\section{B1.Reduction by CO}

The $\mathrm{PdO}$ phase was prepared by oxidation of as-deposited $\mathrm{Pd}$ particles at $673 \mathrm{~K}$ in 1 bar $\mathrm{O}_{2}$ for 1 h (cf. Fig. 3) and subsequently reduced by $\mathrm{CO}$ in $10 \mathrm{~K}$ steps between 423 and $523 \mathrm{~K}$. No changes of the morphology or SAED pattern of PdO could be detected after reduction up to $493 \mathrm{~K}$. Figures 5(a) (electron micrograph) and 5(b) (SAED pattern) denote the state of $\mathrm{PdO}$ after reduction at $493 \mathrm{~K}$. However, we note that after this reduction the PdO phase - although no structural or morphological changes are visible - appears orientationally disordered. The state of the catalyst after a subsequent treatment in $\mathrm{CO}$ at $503 \mathrm{~K}$, under otherwise identical conditions, is shown in Figs. 5(c)5(d). Although most particles still exhibit the typical "disintegrated" structure observed after oxidation at $673 \mathrm{~K}$, some of them (especially in the lower left corner of the micrograph) appear recrystallized with an internal grain boundary, separating their center from the outer regions of the particle. HRTEM images show that $\mathrm{PdO}$ still persists upon reduction at 503 . Some Pd particles are completely reduced. Figure 6(a) shows a single Pd particle with (111) lattice spacings. In contrast, Fig. 6(b) presents a typical PdO grain with (002) lattice fringes surrounded by distorted Pd. This result is confirmed by the diffraction pattern [Fig. 5(d)], which is mainly a superposition of the patterns arising from fcc Pd and tetragonal PdO, neither of which indicates an orientational alignment (two reflections have been marked).

Further increasing the reduction temperature to $513 \mathrm{~K}$ induces even more pronounced changes of the particle structure [Fig. 5(e)]. No particles with a fragmented structure typical for PdO and only very few particles with circular internal boundaries are now observed. The particles appear more rounded, some of them show irregular outlines, but altogether they have readopted the morphology and size distribution of the original Pd metal particles prior to the oxidationreduction cycle. In fact, the corresponding SAED pattern [Fig. 5(f)] shows only reflections of fcc Pd [(111), (200), and (220)]. Interestingly, some broad Pd(200) spot reflections are also seen, indicating that the particles have not lost their complete orientation during oxidation and reduction. This effect is more pronounced in the SAED patterns taken after reduction at $523 \mathrm{~K}$ [Fig. 5(h)]. Four distinct $\operatorname{Pd}(220)$ spots together with a blurred $\mathrm{Pd}(111)$ ring reflection are now discernible. This indicates that during the oxidation-reduction cycle, a defined structural transformation has taken place, whereby at first almost the entire Pd metal is converted into epitaxial oxide and then the original orientation is at least in part reestablished upon reduction. This is only possible if $\mathrm{Pd}$ and $\mathrm{PdO}$ grow in a defined relation with respect to each other, as discussed in Sec. III A. PdO grows in a topotactic relation on the Pd particles, a phenomenon also observed during alloy formation on similar systems under reductive conditions, e.g., $\mathrm{Pt} / \mathrm{SiO}_{2}$, [40] $\mathrm{Rh} / \mathrm{VO}_{x},[41] \mathrm{Pt} / \mathrm{CeO}_{2},[42] \mathrm{Pt} / \mathrm{Al}_{2} \mathrm{O}_{3},[40]$ and $\mathrm{Pd} / \mathrm{Zn} / \mathrm{SiO}_{2}$.[43] In general, this topotactic mechanism seems to be facilitated by the properties of the thin film model systems, in particular, by the large contact area between the regular metal particles and the support. In view of the electron diffraction pattern shown in Fig. 5(h) and the corresponding micrograph [Fig. 5(g)], it can be concluded that reduction in $\mathrm{CO}$ at $523 \mathrm{~K}$ converts the entire $\mathrm{PdO}$ back into metallic $\mathrm{Pd}$. 

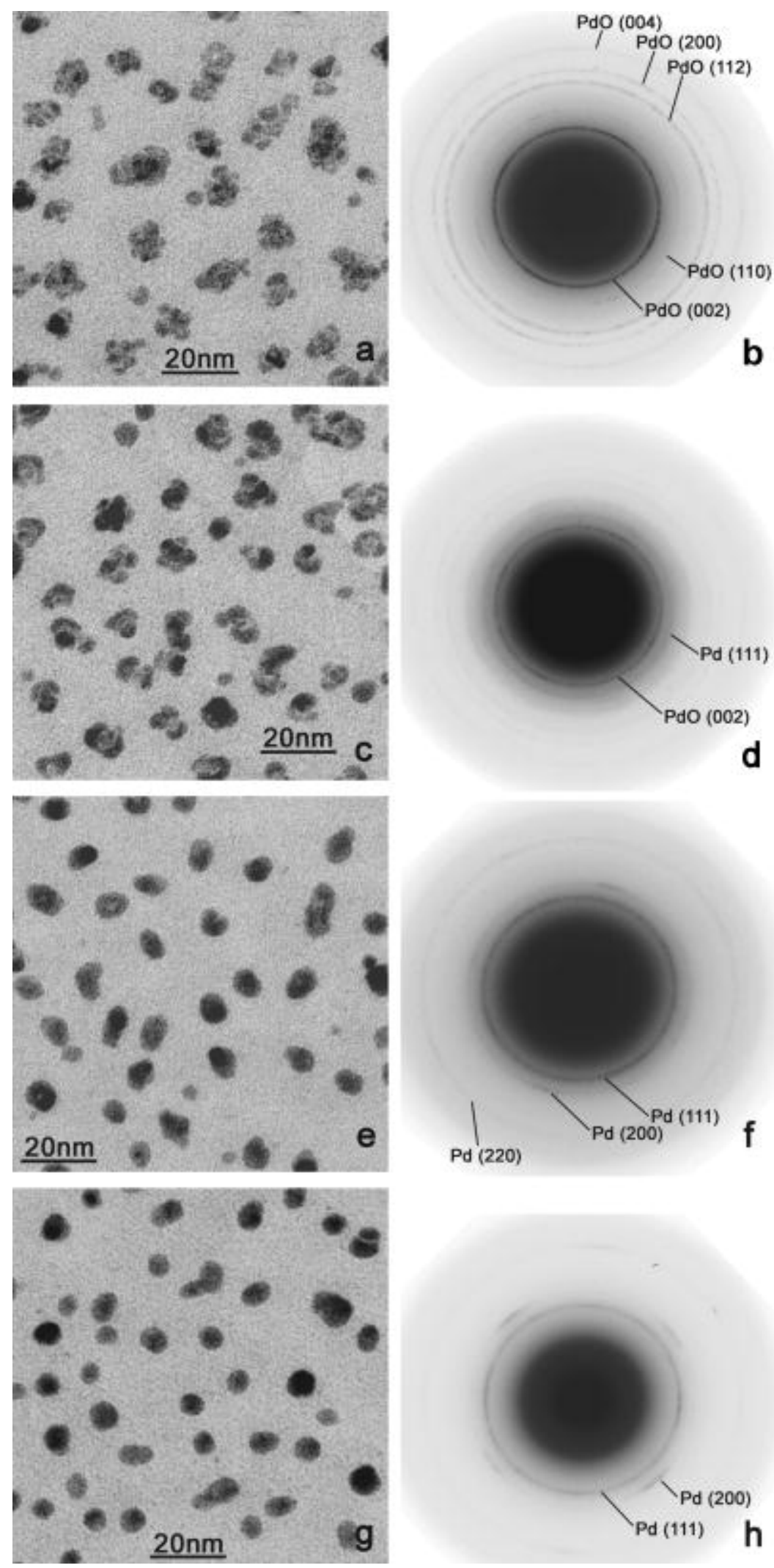

Fig. 5. The $\mathrm{Pd} / \mathrm{SiO}_{2}$ catalyst after an oxidative treatment in 1 bar $\mathrm{O}_{2}$ at $673 \mathrm{~K}$ for $1 \mathrm{~h}$, followed by stepwise reduction in $10 \mathrm{mbar} \mathrm{CO}$ (He added to 1 bar total pressure) for $15 \mathrm{~min}$ at (a) $493 \mathrm{~K}$, (c) $503 \mathrm{~K}$, (e) $513 \mathrm{~K}$, and (g) $523 \mathrm{~K}$. The corresponding SAED patterns are shown in (b), (d), (f), and (h). 

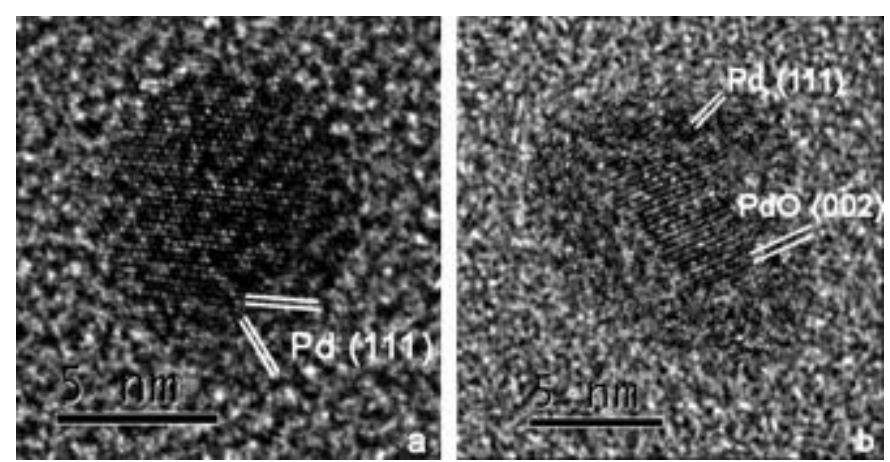

Fig. 6. HRTEM images of the $\mathrm{Pd} / \mathrm{SiO}_{2}$ catalyst after oxidation at $673 \mathrm{~K}$ followed by reduction in $10 \mathrm{mbar} \mathrm{CO}$ at 523 $\mathrm{K}$ for 15 min. (a) Reduced Pd particle with (111) lattice spacings; (b) PdO grain surrounded by partly crystalline Pd.

If we compare our results to single crystal studies on $\mathrm{Pd}(111)$, e.g., by Burghaus et al.[44] and Engel and Ertl,[45] we know that in these cases chemisorbed oxygen exhibits a high activity in the oxidation of $\mathrm{CO}$. Due to the ability of $\mathrm{Pd}$ to coadsorb $\mathrm{CO}$ on an oxygen-precovered surface, the reaction $\mathrm{CO}+\mathrm{O}$ may even take place in oxygen excess. The same is known for the newly discovered $\mathrm{Pd}_{5} \mathrm{O}_{4}$ surface oxide,[46] which is much less active towards $\mathrm{CO}$ than a $\operatorname{Pd}(111)$ surface covered with $0.25 \mathrm{ML}$ of chemisorbed oxygen.[47] However, either of these surfacelimited oxide species already reacts at room temperature under ultrahigh vacuum (UHV) conditions.

Therefore, we tested the stability of an incomplete stage of oxidation, i.e., that after oxidation at $623 \mathrm{~K}$, in order to reveal a possible difference in reduction behavior compared to a completely oxidized $\mathrm{PdO}$ phase. After a reductive treatment in $10 \mathrm{mbar} \mathrm{CO}$ at $503 \mathrm{~K}$ for $10 \mathrm{~min}$, minor amounts of $\mathrm{PdO}$ were still found to persist. Figure 7 shows an agglomerated $\mathrm{PdO}$ grain, exhibiting (002) lattice fringes, besides some disordered particles of unknown composition. This implies (i) that in our case the reduction behavior of the incomplete $\mathrm{PdO}$ phase is not substantially different from that of well developed PdO phase and (ii) that some PdO still persists after reduction. SAED patterns (not shown here) represent a superposition of fcc $\mathrm{Pd}$ and tetragonal $\mathrm{PdO}$ and hence confirm the above HRTEM results.

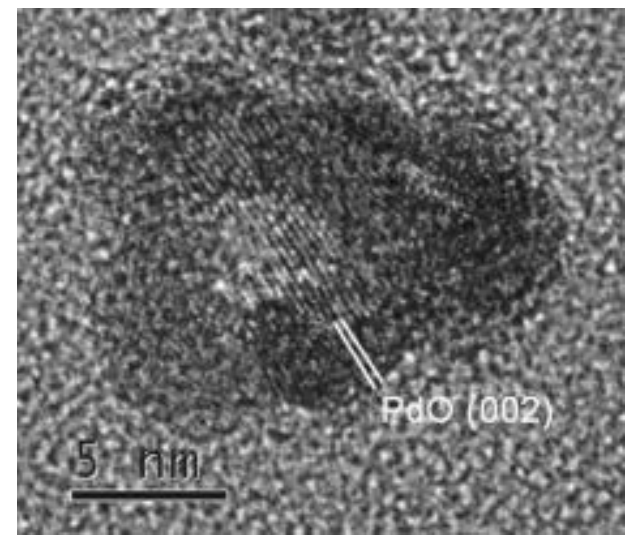

Fig. 7. HRTEM image of the $\mathrm{Pd} / \mathrm{SiO}_{2}$ catalyst after oxidation at $623 \mathrm{~K}$, followed by reduction in $10 \mathrm{mbar} \mathrm{CO}$ at 523 $\mathrm{K}$ for $15 \mathrm{~min}$. $\mathrm{PdO}$ grain surrounded by an agglomerate of amorphous particles.

\section{B2.Thermal stability in He}

As a counterpart to the reduction experiments outlined in the previous section, the thermal stability of $\mathrm{PdO}$ in He was assessed. Figure 8(a) shows the state of the catalyst after annealing in $1 \mathrm{bar} \mathrm{He}$ at $523 \mathrm{~K}$ for $1 \mathrm{~h}$. Obviously, the particles still retain the PdO structure and the SAED 
patterns [Fig. 8(b)] only show reflections due to the tetragonal PdO phase. Raising the annealing temperature to $573 \mathrm{~K}$, however, introduces considerable changes in both particle structure and morphology. The particles have now adopted rounded outlines [Fig. 8(c)] and the SAED patterns are changed towards metallic Pd [Fig. 8(d)]. This means that the decomposition temperature of $\mathrm{PdO}$ under the given reductive conditions $(\mathrm{CO}, 523 \mathrm{~K})$ and upon annealing in $\mathrm{He}(\sim 573 \mathrm{~K})$ differs by about $50 \mathrm{~K}$.
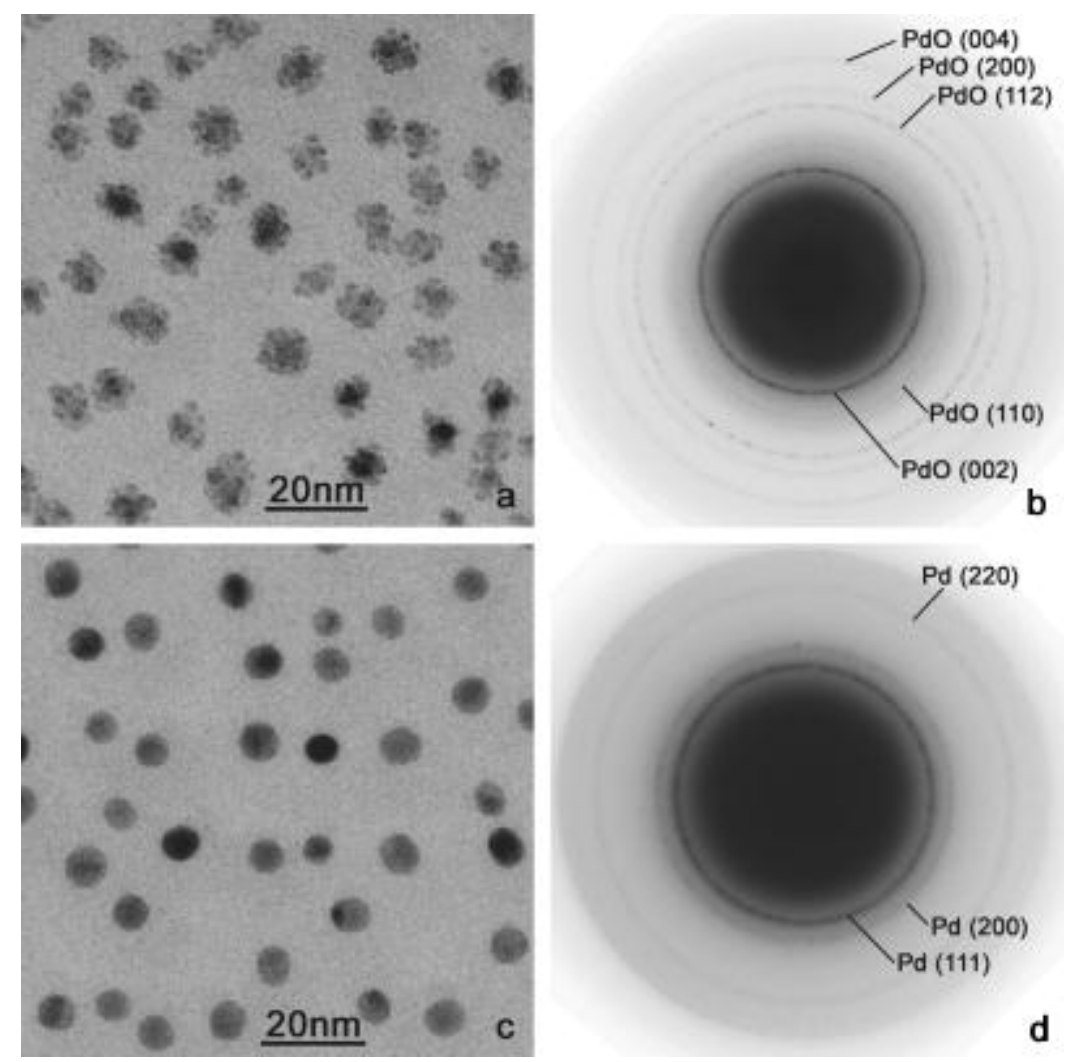

Fig. 8. The $\mathrm{Pd} / \mathrm{SiO}_{2}$ catalyst after an oxidative treatment in 1 bar $\mathrm{O}_{2}$ at $673 \mathrm{~K}$ for $1 \mathrm{~h}$, followed by annealing in 1 bar He for $1 \mathrm{~h}$ at $523 \mathrm{~K}$ (a) and $573 \mathrm{~K}$ (c). The corresponding SAED patterns are shown in (b) and (d).

\section{CONCLUSIONS}

The formation mechanism of $\mathrm{PdO}$ in small particles appears to be strikingly different from that of its counterpart $\mathrm{Rh}_{2} \mathrm{O}_{3}$. While in the latter case a skin of epitaxial $\mathrm{Rh}_{2} \mathrm{O}_{3}$ covers the entire $\mathrm{Rh}$ particle, $\mathrm{PdO}$ forms three-dimensional crystallites on top of the Pd particles in the early stages of oxidation, which show an enhanced mobility as the oxidation temperature increases, thereby moving to the $\mathrm{Pd}-\mathrm{SiO}_{2}$ interface. The difference can be explained tentatively by a predominance of the internal $\mathrm{PdO}$ cohesive energy relative to the $\mathrm{Pd}-\mathrm{PdO}$ interfacial energy; in the $\mathrm{Rh}-\mathrm{Rh}_{2} \mathrm{O}_{3}$ case the opposite trend (higher interfacial energy oxide metal) is probably the driving force of oxide growth. It should, however, be noted that also the PdO crystallites are epitaxially related to the original $\mathrm{Pd}$ particles. Regarding their reduction stability, PdO nanoparticles are more persistent towards CO compared to Pd surface oxides. Clear indications of reduction are only observed at reduction temperatures above $500 \mathrm{~K}$, with most of the PdO being reconverted into partially aligned metallic $\mathrm{Pd}$ at about $520 \mathrm{~K}$. The decomposition of the $\mathrm{PdO}$ nanoparticles in $1 \mathrm{bar}$ He was determined to be completed at about $570 \mathrm{~K}$.

\section{ACKNOWLEDGMENT}

One of the authors (H.G.) thanks the Max-Planck-Society for a research grant. 


\section{REFERENCES}

1. R. Prasad, L. A. Kennedy, and E. Ruckenstein, Catal. Rev. - Sci. Eng. 26, 1 (1984).

2. P. Forzatti and G. Groppi, Catal. Today 54, 165 (1999).

3. E. Garbowski, C. Feumi-Jantou, N. Mouaddib, and M. Primet, Appl. Catal., A 109, 277 (1994).

4. M. Lyubovsky and L. Pfefferle, Appl. Catal., A 173, 107 (1998).

5. T. R. Baldwin and R. Burch, Catal. Lett. 6, 131 (1990).

6. M. Lyubovsky and L. Pfefferle, Catal. Today 47, 29 (1999).

7. R. F. Hicks, H. Qi, M. L. Young, and R. G. Lee, J. Catal. 122, 295 (1990)

8. J. L. Seoane, P. Boutry, and R. Montarnal, J. Catal. 63, 191 (1980).

9. R. J. Ferrauto, M. C. Hobson, T. Kenelly, and E. M. Waterman, Appl. Catal., A 81, 227 (1992).

10. J. G. McCarthy, Catal. Today 26, 283 (1995).

11. A. K. Datye, J. Bravo, T. R. Nelson, P. Atanasova, M. Lyubovsky, and L. Pfefferle, Appl. Catal.A 198, 179 (2000)

12. B. A. Banse and B. E. Koel, Surf. Sci. 232, 275 (1990).

13. G. Zheng and E. I. Altman, Surf. Sci. 462, 151 (2000).

14. B. Klötzer, K. Hayek, C. Konvicka, E. Lundgren, and P. Varga, Surf. Sci. 482-485, 237 (2001).

15. F. P. Leisenberger, G. Koller, M. Sock, S. Surnev, M. G. Ramsey, F. P. Netzer, B. Klötzer, and K. Hayek, Surf. Sci. 445, 380 (2000).

16. K. T. Park, G. W. Simmons, and K. Klier, Surf. Sci. 367, 307 (1996).

17. V. A. Bondzie, P. Kleban, and D. J. Dwyer, Surf. Sci. 347, 319 (1996).

18. E. H. Voogt, A. J. M. Mens, O. L. J. Gijzeman, and J. W. Geus, Surf. Sci. 373, 210 (1997).

19. G. B. Hoflund, H. A. E. Hagelin, J. F. Weaver, and G. N. Salita, Appl. Surf. Sci. 205, 102 (2003).

20. J. Goschnick, M. Wolf, M. Grunze, W. N. Unertl, J. H. Block, and J. Loboda-Cackovic, Surf. Sci. 178, 831 (1986).

21. E. S. Putna, J. M. Vohs, and R. J. Gorte, Surf. Sci. 391, L1178 (1997).

22. G. Zhu, J. Han, D. Y. Zemlyanov, and F. H. Ribeiro, J. Am. Chem. Soc. 126, 9896 (2004)

23. I. Meusel, J. Hoffmann, J. Hartmann, M. Heemeier, M. Bäumer, J. Libuda, and H.-J. Freund, Catal. Lett. 71, 5 (2001)

24. M. Lyubovsky, L. Pfefferle, A. Datye, J. Bravo, and T. Nelson, J. Catal. 187, 275 (1999)

25. N. M. Rodriguez, S. G. Oh, R. A. Dalla Betta, and R. T. K. Baker, Stud. Surf. Sci. Catal. 88, 417 (1994)

26. K.-I. Fujimoto, F. H. Ribeiro, M. Avalos-Borja, and E. Iglesia, J. Catal. 179, 431 (1998)

27. H. Graoui, S. Giorgio, and C. R. Henry, Surf. Sci. 417, 350 (1998)

28. S. Giorgio, C. R. Henry, C. Chapon, and C. Roucau, J. Catal. 148, 534 (1994)

29. C. Henry, Prog. Surf. Sci. 80, 92 (2005)

30. J. J. Chen and E. Ruckenstein, J. Phys. Chem. 85, 1606 (1981)

31. M. Chen and L. D. Schmidt, J. Catal. 56, 198 (1979)

32. G. Rupprechter, K. Hayek, and H. Hofmeister, J. Catal. 173, 409 (1998)

33. W. Unterberger, H. Gabasch, K. Hayek, and B. Klötzer, Catal. Lett. 104, 1 (2005)

34. JCPDS-International Center for Diffraction Data, Card No. 00-006-0515, 2005 (unpublished); H. E. Swanson, P. T. Gilfrich, and G. M. Ligrinic, Standard X-Ray Diffraction Powder Patterns, Natl. Bur. Stand. (U.S.), Circ. No. 539 (U.S. GPO, Washington, DC, 1955), Vol. 4, p. 27.

35. T. Schalow, M. Laurin, B. Brandt, S. Schauermann, S. Guimond, H. Kuhlenbeck, D. E. Starr, S. K. Shaikhutdinov, J. Libuda, and H.-J. Freund, Angew. Chem., Int. Ed. 44, 7601 (2005)

36. T. Schalow, B. Brandt, D. E. Starr, M. Laurin, S. Schauermann, S. K. Shaikhutdinov, J. Libuda, and H.-J. Freund, Catal. Lett. 107, 189 (2006)

37. G. Rupprechter, G. Seeber, H. Goller, and K. Hayek, J. Catal. 186, 201 (1999)

38. J. Gustafson, A. Mikkelsen, M. Borg et al., Phys. Rev. Lett. 92, 126102 (2004)

39. S. Aggarwal, A. P. Monga, S. R. Perusse, R. Ramesh, V. Ballarotto, E. D. Williams, B. R. Chalamala, Y. Wei, and R. H. Reuss, Science 287, 2235 (2000).

40. S. Penner, D. Wang, D. S. Su, G. Rupprechter, R. Podloucky, R. Schlögl, and K. Hayek, Surf. Sci. 532, 276 (2003)

41. S. Penner, B. Jenewein, D. Wang, R. Schlögl, and K. Hayek, Phys. Chem. Chem. Phys. 8, 1223 (2006).

42. S. Penner, D. Wang, R. Podloucky, R. Schlögl, and K. Hayek, Phys. Chem. Chem. Phys. 6, 5244 (2004). 
43. S. Penner, B. Jenewein, H. Gabasch, B. Klötzer, D. Wang, A. Knop-Gericke, R. Schlögl, and K. Hayek, J. Catal. 241, 14 (2006).

44. U. Burghaus, I. Z. Jones, and M. Bowker, Surf. Sci. 454, 326 (2000)

45. T. Engel and G. Ertl, Adv. Catal. 28, 1 (1979)

46. E. Lundgren, G. Kresse, C. Klein, M. Borg, J. N. Andersen, M. De Santis, Y. Gauthier, C. Konvicka, M. Schmid, and P. Varga, Phys. Rev. Lett. 88, 246103 (2002)

47. H. Gabasch, Ph.D. thesis, University of Innsbruck, 2006 